\title{
Síndrome de activación macrofágica por COVID-19 en el adulto
}

\author{
Lorena Salmerón-Godoy, Adrián López-Alba, Elena Arranz-Canales \\ Servicio de Medicina Interna, Hospital Universitario 12 de Octubre, Madrid, España
}

Recibido: 16/10/2020

Aceptado: 03/12/2020

En línea: 30/04/2021

Citar como: Salmerón-Godoy L, López-Alba A, Arranz-Canales E. Síndrome de activación macrofágica por CoVID-19 en el adulto. Rev Esp Casos Clin Med Intern (RECCMI). 2021 (abril); 6(1): 3-6. doi: 10.32818/reccmi.a6n1a2.

Cite this as: Salmerón-Godoy L, López-Alba A, Arranz-Canales E. Macrophage activation syndrome by COVID-19 in the adult. Rev Esp Casos Clin Med Intern (RECCMI). 2021 (April); 6(1): 3-6. doi: 10.32818/reccmi.a6n1a2.

Autor para correspondencia: Lorena Salmerón-Godoy. lorenasalmerongodoy@hotmail.com

\begin{tabular}{l} 
Palabras clave \\
\hline$\triangleright$ COVID-19 \\
$\triangleright$ SARS-CoV-2 \\
$\triangleright$ Tormenta citocínica \\
$\triangleright$ Síndrome de activación \\
$\quad$ macrofágica \\
$\triangleright$ Inflamación
\end{tabular}

\section{Keywords}

$\triangleright$ COVID-19

$\triangleright$ SARS-COV-2

$\triangleright$ Cytokinestorm

$\triangleright$ Macrophage activation syndrome

$\triangleright$ Inflammation

\section{Resumen}

La COVID-19 es una infección con un curso clínico heterogéneo. La mayoría de los casos se presenta asíntomática o paucisintomática. Sin embargo, algunos pacientes pueden desarrollar complicaciones inmunológicas como el síndrome de activación macrofágica, que resulta en una tormenta de citocinas, y el síndrome de distréss respiratorio agudo.

Presentamos el caso atípico de un varón de 38 años que ingresa por sospecha de probable síndrome linfoproliferativo, con diagnóstico final de síndrome inflamatorio multisistémico en relación a infección vírica por COVID-19 sin afectación pulmonar, con evento trombótico arterial asociado a nivel esplénico.

Abstract
The COVID-19 infection has a heterogenous disease course. It may be asymptomatic or paucisymptomatic.
However, immunologic complications such as macrophage activation sindrome, resulting in cytokine storm
syndrome, and acute respiratory distress syndrome, may also occur in some patients.
We describe an atypical case of a 38-year-old man admitted to study in clinical suspicion of lymphoproliferative
síndrome, whose final diagnosis was macrophage activation syndrome by COVID-19 infection without respira-
tory symptoms and an arterial thrombotic splenic event associated.

\section{Puntos destacados}

$\triangleright$ La implicación de la respuesta inflamatoria asociada a la infección COVID-19 da lugar en algunos casos a un síndrome de activación de macrófagos como principal manifestación clínica.

$\triangleright$ Estos pacientes frecuentemente presentan un estado protrombótico con posibles complicaciones secundarias.

\section{Introducción}

La COVID-19 es un síndrome clínico causado por un virus RNA llamado Severe Acute Respiratory Syndrome CoronaVirus 2 (SARS-CoV-2). Es una infección con un curso clínico heterogéneo, en la que la mayoría de los casos se presenta asintomática o paucisintomática. Sin embargo, en algunos pacientes, existen complicaciones inmunológicas como el síndrome de activación macrofágica (SAM), que resulta en una tormenta de citocinas, y el síndrome de distrés respiratorio agudo (SDRA).
El objetivo de este caso es demostrar la dificultad del diagnóstico en estos pacientes con cuadros clínicos atípicos, sin afectación pulmonar y la necesidad de descartar otras etiologías con tratamientos específicos.

\section{Caso clínico}

\section{Antecedentes personales}

Varón de 38 años natural de Perú, residente en España desde 2005, sin antecedentes médico-quirúrgicos relevantes, a excepción de obesidad. Acude a Urgencias por 15 días de fiebre (hasta $39,5^{\circ} \mathrm{C}$ ), odinofagia y artromialgias sobre todo en miembros inferiores, ageusia y anosmia, tos con expectoración blanquecina, diarrea y vómitos bilioalimentarios.

El paciente es soldador (trabaja con aluminio. Niega viajes recientes, contacto con animales o el medio rural, sin ambiente epidemiológico infeccioso ni consumo de tóxicos. 


\section{Exploración física}

Durante la hospitalización, hemodinámicamente está estable, con saturación parcial, oxígeno 95\% basal sin datos de trabajo respiratorio y temperatura $37,3^{\circ} \mathrm{C}$. Destaca en la exploración únicamente hepatoesplenomegalia palpable.

\section{Pruebas complementarias}

Analíticamente: hemograma y función renal normal; alteración mixta del perfil hepático (GPT 121UI/L, GOT 120 UI/L, FA 120 UI/L, GGT 122 UI/L, bilirrubina $0,6 \mathrm{mg} / \mathrm{dL}$ ) y elevación de reactantes con Ferritina $30000 \mathrm{ng} / \mathrm{m} \mathrm{L,} \mathrm{LDH} 710 \mathrm{UI} /$ L, VSG 85 y PCR $6,04 \mathrm{mg} / \mathrm{dL}$, así como unos dímeros D $5621 \mathrm{ng} / \mathrm{mL}$ con resto de la coagulación normal (Tabla 1).

Microbiológicamente, se extraen hemocultivos que resultan estériles y se realizan 2 pruebas de PCR para SARS-CoV-2 en exudado nasofaríngeo que resultaron negativas. Ante la sospecha de infección por COVID-19 y enfermedad trombótica asociada, se realizó TC toraco-abdomino-pélvico que descarta afectación pulmonar y evidencia hepatoesplenomegalia (bazo de $15 \mathrm{~cm}$ ) y múltiples adenopatías infra y supradiafragmáticas de un tamaño máximo de $1,5 \mathrm{~cm}$ (paratraqueales, hiliares, retroperitoneales, ilíacas e inguinales), además de pequeño infarto esplénico subagudo (Figura 1). Al revisar las imágenes se objetiva un defecto de repleción no oclusivo en la rama de arteria esplénica probablemente relacionada con un pequeño trombo/émbolo.

En PET-TC se objetivaron múltiples adenopatías hipermetabólicas supra e infradiafragmaticas sugestivas de síndrome linfoproliferativo de alto grado e incremento difuso del metabolismo en médula ósea que impresiona de etiología reactiva sin poder descartar posible infiltración (Figuras 2, 3 y 4).

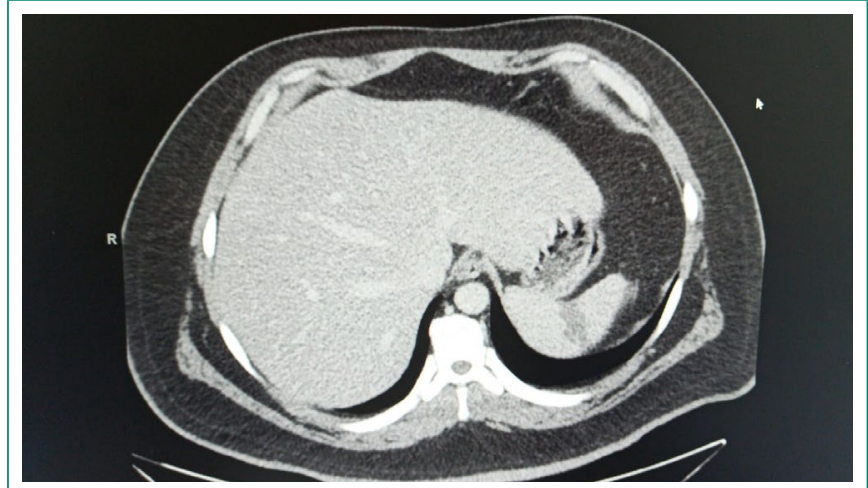

Figura 1. Infarto esplénico en imagen de TC.

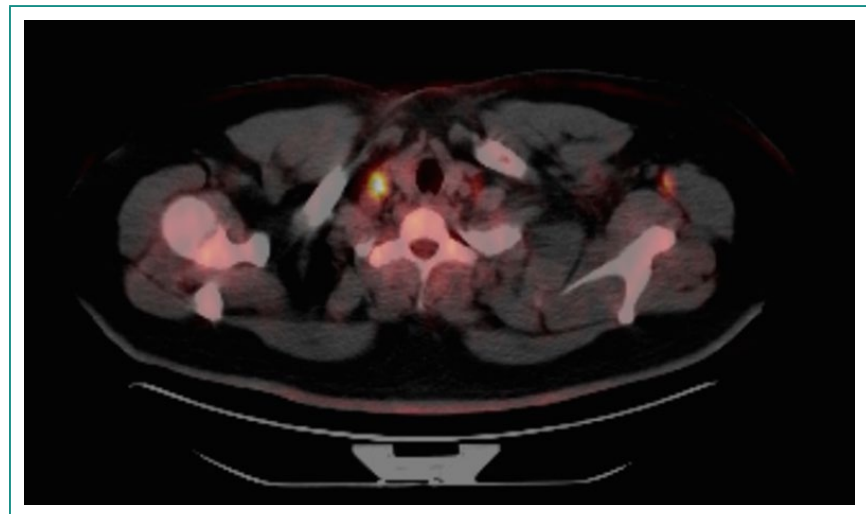

Figura 2. Adenopatía submaxilar y adenopatías torácicas con hipercaptación en imagen de PET-TC.

\begin{tabular}{|c|c|c|c|c|}
\hline Parámetro analítico & Al ingreso & Al alta & En revisión & V. Referencia \\
\hline Hemoglobina (g/dL) & 14,0 & 13,3 & 15,3 & $13,0-16,8$ \\
\hline Plaquetas (por microlitro) & 148.000 & 222.000 & 176.000 & $140-450 \times 1.000$ \\
\hline Leucocitos (por microlitro) & 10.800 & 5.500 & 7.100 & $4-11,3 \times 1.000$ \\
\hline Neutrófilos (por microlitro) & 8.000 & 3.300 & 3.500 & $1,8-7,4 \times 1.000$ \\
\hline Linfocitos (por microlitro) & 1.400 & 1.300 & 2.700 & $1,2-4,0 \times 1.000$ \\
\hline Creatinina $(\mathrm{mg} / \mathrm{dL})$ & 0,80 & 0,73 & 0,79 & $0,7-1,2$ \\
\hline Sodio (mEq/L) & 136 & 138 & 142 & $136-145$ \\
\hline Potasio (mEq/L) & 3,70 & 4,12 & 4,21 & $3,5-5,1$ \\
\hline ALT/GPT (UI/L) & 121 & 58 & 85 & $5-45$ \\
\hline AST/GOT (UI/L) & 120 & 37 & 40 & $5-33$ \\
\hline GGT (UI/L) & 122 & 61 & 28 & $8-61$ \\
\hline Fosfatasa alcalina (UI/L) & 120 & 68 & 49 & $40-130$ \\
\hline Bilirrubina total (mg/dL) & 0,6 & 0,6 & 0,8 & $0,2-1,0$ \\
\hline Triglicéridos (mg/dL) & 215 & & 285 & $50-200$ \\
\hline Lactato deshidrogenasa (UI/L) & 710 & 305 & 228 & $135-225$ \\
\hline Ferritina (ng/mL) & 30.000 & 2.500 & 140 & $30-400$ \\
\hline Proteina C reactiva (mg/dL) & 6,04 & 0,23 & 0,10 & $0,10-0,50$ \\
\hline Velocidad sedimentación (mm) & 85 & 17 & 16 & $0-20$ \\
\hline Actividad protrombina (\%) & 79 & 80 & 91 & $75-140$ \\
\hline TTPa (sec) & 32 & 36 & 37 & $26-39$ \\
\hline Dímero $\mathrm{D}(\mathrm{ng} / \mathrm{mL})$ & 5.621 & 2.200 & 56 & $0-500$ \\
\hline
\end{tabular}

Tabla 1. Evolución de resultados de laboratorio 


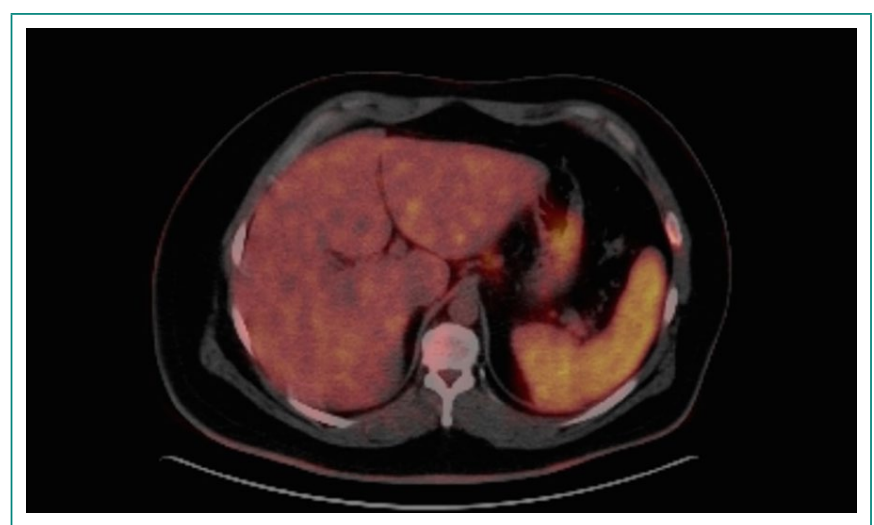

Figura 3. Hepatoesplenomegalia en PET-TC.

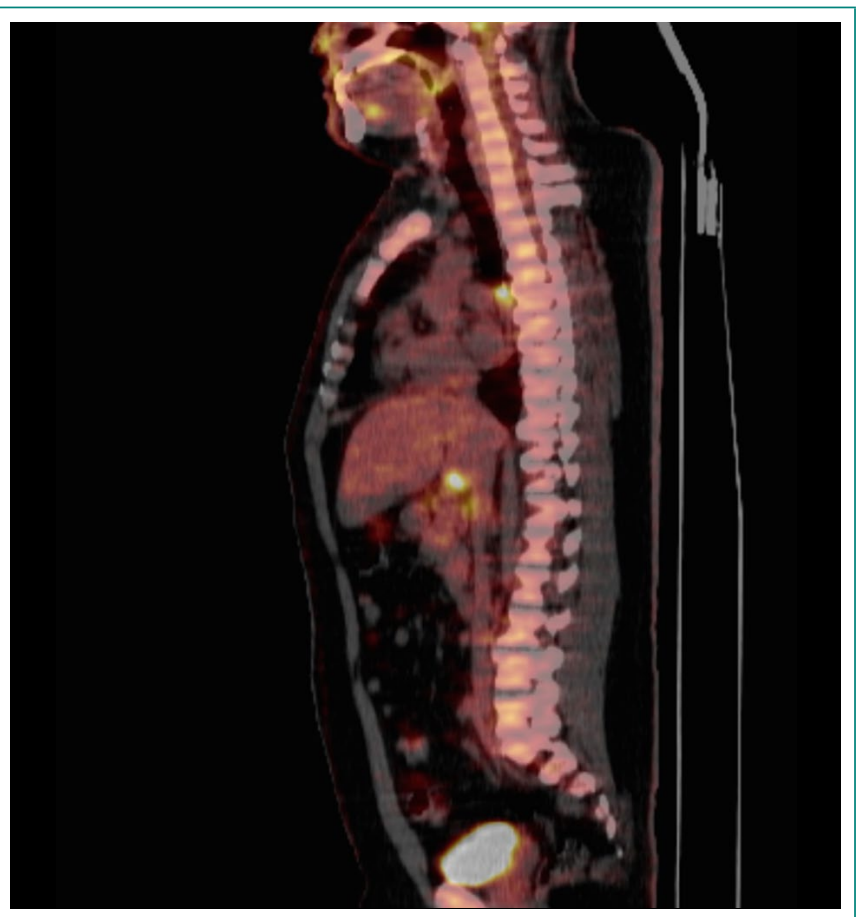

Figura 4. Adenopatias submaxilar y torácicas hipercaptantes en PET-TC.

Se tomó biopsia médula ósea en la que se observó linfoplasmocitosis intersticial de aspecto reactivo sin signos de malignidad, con cultivo y PCR para leishmania negativo. Dado la normalidad del resultado, se realizó biopsia abierta de adenopatía submaxilar también de aspecto reactivo y sin datos de malignidad. Se completó el estudio con electroforésis que mostraba hipergammaglobulinemia policlonal y bandas oligoclonales kappa y lambda en inmunofijación, beta2microgobulina normal, hipertrigliceridemia leve $215 \mathrm{mg} / \mathrm{dL}$, con autoinmunidad negativa y complemento y CD25 soluble normal. Además el frotis y citometría de flujo de sangre periférica resultaron también de aspecto reactivo.

Por último, se obtuvieron serologías con hallazgos de infección pasada para VHA, CMV y VEB y negativas para VIH, toxoplasma, VHB y VHC. El IGRA y el antígeno de leishmania en orina resultaron negativos. Finalmente se recibe el resultado de la serología lgM e IgG SARS-CoV2 en plasma positiva.

Con respecto al infarto subagudo esplénico se realizó el estudio de trombofilia que fue normal, únicamente, en una primera determinación, resultaron levemente positivos los anticuerpos antifosfolípido (anticoagulante lúpico: razón VDRR 1.16).

\section{Evolución}

La evolución del paciente con tratamiento sintomático basado en antitérmicos convencionales fue favorable, con descenso de reactantes (PCR 0,23: ferritina 2500; LDH 300) y PET-TC ambulatorio de reevaluación normal. Una segunda determinación de anticuerpos antifosfolípido resultó negativa, por lo que tras completar 3 meses de anticoagulación se retira.

\section{Juicio diagnóstico}

Dado el cuadro clínico, analítico y radiológico, así como los resultados histológicos/microbiológicos y evolución del paciente, se asumió el diagnóstico síndrome de activación macrofágica secundario por posible infección por SARS-CoV-2 con evento trombótico arterial asociado. Si bien es cierto que el caso es orientativo de infección aguda por COVID 19, no se puede confirmar al carecer de PCR/Antígeno o datos de seroconversión para SARS-COV-2.

\section{Discusión y conclusión}

EI SARS-CoV-2 es un tipo de coronavirus recientemente conocido que causa principalmente infección respiratoria de gravedad variable, responsable de la pandemia mundial actual. Debido al escaso tiempo de evolución de la infección, aún se desconocen muchos aspectos; sin embargo, se ha descrito claramente la implicación de la respuesta inmunitaria en la patogenia de dicha enfermedad.

Se ha demostrado que el SARS-CoV-2 puede provocar una respuesta inflamatoria, que implica una activación y liberación de citocinas inflamatorias en un circuito de retroalimentación positiva de la inflamación. Esta tormenta de citocinas es una de las principales causas de morbi-mortalidad por COVID-19 1 -4

La hipercitocinemia se encuentra típicamente en el SAM, estado de hiperinflamación sistémica que, a menudo, se observa en pacientes con infecciones, neoplasias malignas o enfermedades reumatológicas ${ }^{1,2}$. Similar al SAM, en la infección grave por COVID-19 se ha evidenciado regulación al alza de IL-1 $\beta$, IL-2, IL-6, IL-7, IL-17 y TNF-a; así como aumento de ferritina, PCR y dímero D, que son marcadores séricos de inflamación grave y fibrinólisis ${ }^{1-4}$.

La manifestación clínica en forma de SAM con ausencia o leve afectación pulmonar se ha descrito en los pacientes con infección por COVID-19 en edad pediátrica o adolescencia ${ }^{5}$ pero no adultos. Asimismo, aunque puede estar presente la afectación pulmonar en el cuadro clásico de SAM, su afectación predominante es a otros niveles (fiebre, adenopatías, hepatoesplenomegalia, citopenias, alteración de la función hepática y activación de la cascada de coagulación intravascular)². Además, estos pacientes no cumplen la mayoría de veces completamente los criterios clásicos de diagnóstico de SAM, como en el caso presentado. Por estos motivos, esta manifestación clínica asociada a la infección por SARS-CoV-2 se ha descrito como SAM-like, dado que la inmunopatología se localiza principalmente a nivel pulmonar, del tejido linfoide y vascular asociado, desarrollándose un SDRA².

Por otro lado, esta tormenta de citocinas provoca la activación de las células endoteliales e hiperviscosidad sanguínea. Junto con el daño provocado por la unión viral al receptor ACE-2, el aumento de niveles de anticuerpos anticardiolipina y otros factores asociados a estos pacientes (ventilación mecánica, catéteres vasculares), puede resultar en un estado protrombótico, principalmente a nivel pulmonar pero también a otros niveles, como en este caso a nivel esplénico ${ }^{6}$ 
Dada la clara implicación patogénica de la tormenta de citocinas en esta infección, es de gran interés saber si los tratamientos anticitocinas (utilizados en SAM) también son efectivos en el tratamiento de COVID-19, como los glucocorticoides o tocilizumab $b^{6-8}$.

Este caso representa un reto diagnóstico, que pone de manifiesto la implicación de la respuesta inflamatoria y la tormenta de citocinas asociadas a la infección COVID-19, dando lugar a un cuadro clínico que simula un síndrome linfoproliferativo. Además, revela la posible afectación sistémica con escasa expresividad pulmonar, sin haberse descrito frecuentemente en estos pacientes, así como la relación ya descrita previamente de la COVID-19 con alteraciones de la coagulación.

\section{Bibliografía}

1. Otsuka R, Seino KI. Macrophage activation syndrome and COVID-19. Inflamm Regen. 2020; 40: 19. doi:10.1186/s41232-020-00131-w.

2. McGonagle $D$, Sharif $K$, O'Regan A. The Role of Cytokines including Interleukin-6 in COVID-19 induced Pneumonia and Macrophage Activation Syndrome-Like Disease. Autoimmun Rev. 2020; 19(6): 102537. doi:10.1016/j. autrev.2020.102537.
3. Quirch M, Lee J, Rehman S. Hazards of the Cytokine Storm and CytokineTargeted Therapy in Patients With COVID-19: Review. J Med Internet Res. 2020; 22(8): e20193. doi:10.2196/20193.

4. Paces J, Strizova Z, Smrz D, Cerny J. COVID-19 and the immune system. Physiol Res. 2020; 69(3): 379-388. doi:10.33549/physiolres.934492.

5. Whittaker E, Bamford A, Kenny J, Kaforou M, Jones CE, Shah P, et al.; PIMS-TS Study Group and EUCLIDS and PERFORM Consortia. Clinical Characteristics of 58 Children With a Pediatric Inflammatory Multisystem Syndrome Temporally Associated With SARS-CoV-2. JAMA. 2020; 324(3): 259-269. doi: 10.1001/jama.2020.10369.

6. Soy M, Keser G, Atagündüz P. Cytokine storm in COVID-19: pathogenesis and overview of anti-inflammatory agents used in treatment. Clin Rheumatol. 2020; 39(7): 2085-2094. doi:10.1007/s10067-020-05190-5.

7. Mehta P, Porter JC, Manson JJ, Isaacs JD, Openshaw PJM, McInnes IB, et al. Therapeutic blockade of granulocyte macrophage colony-stimulating factor in COVID-19-associated hyperinflammation: challenges and opportunities. Lancet Respir Med. 2020; 8(8): 822-830. doi:10.1016/S2213-2600 (20) 30267-8.

8. Siemieniuk RA, Bartoszko JJ, Ge L, Zeraatkar D, Izcovich A, Kum E, et al. Drug treatments for covid-19: living systematic review and network meta-analysis. BMJ 2020; 370: m2980. doi: 10.1136/bmj.m2980. 